\title{
DISCUSSION
}

\section{Delayed collapse of cut slopes in stiff clay}

\author{
D. M. POTTS, N. KOVACEVIC and P. R. VAUGHAN (1997). Géotechnique 47, No. 5, 953-982
}

\author{
E. N. Bromhead ${ }^{*}$ and N. Dixon $\dagger$, ${ }^{*}$ Kingston University, UK, \\ $\dagger$ Nottingham Trent University, UK
}

Professor Potts and his colleagues have, in this paper, produced some remarkable and exciting results, which are the culmination of at least 50 years of research in soil mechanics, and which provide answers to problems which perplexed engineers over 150 years ago (Gregory (1844) remarks: 'The sudden and extensive failure of so large a quantity of earth, in works constructed with every appearance of solidity ...' and 'The slopes having generally remained for some time at the inclination at which they were formed, it may be inferred, that some fresh action must have developed, by which the equilibrium was destroyed.' He identifies this fresh action as the effect of water-not so very far from the authors' conclusions!)

The base boundary condition assumed in the finite element analyses has an important bearing on the results obtained. In the analysis, the authors have taken it to be rigid-rough and at what appears to be a relatively shallow depth below the excavation base.

A rigid-smooth assumption causes the loads formerly carried by the soil which has been excavated to crush the remaining soil below the base of the excavation, and this is clearly different from field behaviour. However, the rigid-rough approximation causes a shear transfer to occur which does depend to some extent on the assumed hard base depth, and is different to that which would occur if the deflections of lower strata were to be included. At the cost of some small additional complexity in the analysis, spring supports can be incorporated. It is to be expected that the eventual shape of the rupture surface would depend on this transfer of shear stress. It was therefore interesting to note that, in the author's analyses, the slide surface moved back further into the slope with higher $K_{0}$ factors, and this movement does, to some degree, depend on the base boundary condition. It would be useful to see if varying the depth to the base of the mesh and its support conditions changed the failure surface. No such effect can ever be discerned when using a limit equilibrium analysis.

Increasing soil stiffness with depth (the 'Gibson' soil) also insulates the slope from the base boundary condition to a certain degree.

We raise this point because in cases where a rigid base boundary provides a geological control to the eventual slip surface location (examples are legion, but see Gregory (1844), Bromhead (1978), Hutchinson (1969), Hutchinson et al. (1980, 1991) and Bromhead et al. (1992), it is tempting to see the development of the slip surface close to the base of a clay layer as a response to a concentration of shear strain. Our recollection of the Saxon Pit study is that the basal shear there was also bedding-controlled. However, the authors have produced a horizontal shear surface, and one which in some cases retreats further under the slope than the eventual collapse slide surface backslope, without any implicit geological structure-except, of course, for the mesh geometry itself. It is in our opinion critical that the possibility that this slide surface development is a computational or modelling artifact should be dispelled by repeating the analyses with a different mesh configuration, or some other assurance that this possibility has been examined and rejected for sound reasons.

The authors' attention is drawn to the paper on the controlled slope failure at Selborne (Cooper et al., 1998), where many of the effects noted in their paper have been observed in the field.

Naturally, with such a powerful tool as ICFEP at their disposal, the authors can be disparaging about limit equilibrium methods. It would be useful to debate this. For instance, the use of an average $r_{\mathrm{u}}$ value in slope stability analyses implies both a distribution as well as an average magnitude of the pore water pressures (Bromhead, 1986). It can change the location of the critical slip circle in a search analysis in homogeneous material by at least as much as the difference between the authors' surfaces in Fig. 11. Using a better pore water pressure distribution in the limit equilibrium analysis, in our experience, is critical.

Slip surfaces in limit equilibrium can also be shapes other than a circle, for example log spirals or with flat-soled composite shapes. Agreement between the complex analyses presented in this paper and the simple, approximate, limit equilibrium results is remarkably good. The results presented in this paper actually provide much comfort to a practitioner using the empirical 'fully softened' strength and a simple limit equilibrium method. We suspect that the results would be obtained in very much quicker time, and at significantly lesser cost, than by running ICFEP as a design tool.

Bromhead (1978), Dixon \& Bromhead (1991) and Cooper et al. (1998) all report good results from the combination of limit equilibrium analysis, 'fully softened' strength, pore pressures at failure derived from measurement or deduced from related measurements, and the onset of collapse. The first two cases are in bigger slopes than are considered in this paper, but still in London Clay, and the latter case is in a different geological material (Gault). It is reassuring to discover that there is some reason behind this. As an aside, surely, following the series of publications which include Skempton \& Chandler (1970), no-one today designs cut slopes on the peak shear strength (page 965)? Also on this page, the authors state that absolute values of the displacement vectors are of no significance. Clearly, this refers to the analysis, where the precise strains at which peak and residual are developed is unknown, and where, in the analysis, displacement magnitude does not influence the results. Clearly, pre-failure deformations are, or can be, of extraordinary importance. It is important that appreciable strains develop long before collapse. Perhaps on a grassy motorway slope, they are truly of little or no importance. Where the crest of the slope is occupied by a paved area, or buildings, or where buried pipes run down the slope face, the magnitude of ground strains is vital, and this work does show that the onset of appreciable and detectable ground strain can occur while the slope is unready for collapse (i.e. at $F>1$ ) -an important result, again confirmed in the field (Cooper et al., 1998).

There must be, in any continuum analysis, some remaining doubt as to whether residual strength conditions have been induced. In this paper, the authors consider a plastic strain of $20 \%$ as sufficient to generate residual strength. This seems rather small, and therefore, apart from the very toe of the slope, where large absolute deflections are indicated, we doubt that a field investigation would reveal fully developed slickensided shears at this stage.

The use of a suction as the surface boundary condition is an important part of the modelling, as is the use of a small effective cohesion. Both of these effects prevent the analysis indicating very shallow surface sloughs as a mode of failure. Vegetation obviously has a role in this. Clearly, however, bare slopes or slopes with positive boundary pressures, which occur particularly under snow melt (where run-off is inhibited), may not conform to this model. In addition, the shear strength at 
zero effective stress may not be entirely properly represented by the cohesion intercept of a line which is a good fit to shear strength test results at a higher effective stress range.

Figure 17 is of particular interest to us, in showing pore pressure reduction beyond the slope crest. This effect has been detected in the field (Bromhead \& Dixon, 1984).

We were also interested to discover if the shape of the eventual slip surface depended in any way on the excavation sequence, since, in this cut slope case, excavation is presumably by removing layers. In a natural slope subject to erosion, or a cut slope which is widened, the removal of material may preserve the eventual slope shape as it is driven back into natural ground. This could be an interesting result, whatever way the analyses predict.

\section{Authors' reply}

The authors thank Professor Bromhead and Dr Dixon for their full discussion. First, we will make some general points. The work reported in the paper was performed seven years ago. Computer power was limited, which restricted the number of runs. The programme ICFEP was less developed than it is now. For instance, permeability was modelled as a constant which did not vary with effective stress. This is necessary for realistic modelling of swelling. Finally, the results depend on a number of soil parameters (not required in conventional limit equilibrium analyses) for which there was then and still is little hard data.

There are limitations in using a continuum program to examine problems in which discontinuities develop. Experience with ICFEP has shown that a shear zone with strain softening can be simulated on the scale of half an element thickness. For the analyses this is about $0.5 \mathrm{~m}$. Thus a shear surface is modelled by a much thicker zone. A thin zone can only be modelled if many more elements are used. Special elements cannot be adopted, as the location of the rupture surface is not known at the outset. The soil parameters were adopted to give equivalence between a natural shear surface and the wider shear zone in the analysis (see Fig. 6 of the paper). At present, procedures for automatically refining finite element meshes during an analysis are being developed, and these may help with softening analysis in the future. However, there will still be uncertainties associated with specifying the constitutive behaviour.

The rate of strain softening on a shear surface in the field is a major uncertainty. Studies of the Carsington failure (Potts et al., 1990) indicated that it is not as important as might be expected. Figs 13 and 14 of the paper show that the predicted length of the eventual rupture surface lying between peak and residual is quite short. Changing it would have only a modest effect. Probably of greater significance in modelling a shear surface by a wider zone is the angle of dilation, $v$, as discussed in the paper.

No systematic studies of sensitivity of results to element size were made. Previous experience indicated that the meshes used were fine enough.

Incremental displacements are plotted to show the mechanism of current movement. Their magnitude depends on increment size, etc., and is of no significance (page 965 of the paper). Total displacements are of great engineering significance, as Professor Bromhead and Dr Dixon rightly state.

Professor Bromhead and Dr Dixon are right to stress the importance of a rigid lower boundary in concentrating strain and promoting progressive failure. In many of the analyses, a secondary rupture surface began to develop from the toe dipping down towards the rigid base (not presented in the paper for reasons of space). The incipient development of such a surface is shown in Fig. 15. This secondary mechanism was always separate from the primary rupture surface and never combined with it. In one analysis of a $10 \mathrm{~m}$ high slope, the depth of the base was increased from $10 \mathrm{~m}$ to $20 \mathrm{~m}$ below the toe. The secondary mechanism then separated from the base. The 'softer' base gave a slight reduction in the amount of progressive failure but the position of the rupture surface was virtually unchanged. The section analysed involves a $30 \mathrm{~m}$ deep uniform deposit of clay, which may be rare in nature. In reality, $K_{0}$ would decrease with depth, which would also decrease progressive failure. The deep-seated secondary rupture surface might be partly due to the failure to model this reduction in the analyses. The general effect of changing properties with depth needs further examination, but the number of variables involved is large.

The authors consider that there are many pitfalls in seeking to 'calibrate' conventional limit equilibrium analyses from continuum analyses such as those presented in the paper. It is demonstrated in the paper that the agreement is good if there is no strain softening. With strain softening, a similar answer is obtained by limit equilibrium if the average operational strength from the finite element analysis is used, together with the rupture surface from the same analysis and with similar internal force distributions. However, if this strength is used in a limit equilibrium search process then a differrent rupture surface and a different safety factor will be found. A limit equilibrium analysis will not necessarily predict the rupture surface which will develop in a strain-softening material unless this is fixed by the problem geometry. Limit equilibrium analysis can estimate the average operational strength along an actual rupture surface if this is known. However, this strength cannot be reused in a search process.

The authors view is that, if limit equilibrium methods are to be used in strain softening materials, it is safer to use both a search technique and a strength obtained directly by using this technique to analyse field failures. The process is semi-empirical but is consistent.

Professor Bromhead and Dr Dixon discuss the use of 'fully softened strength' with limit equilibrium analysis. This strength is conceptual rather than actual. It is usually taken to be equivalent to the strength of the clay in a normally consolidated state $\left(c^{\prime}=0\right)$. The old hypothesis that this strength might actually exist due to reconsolidation of softened clay around fissures has long been abandoned. The approach using fully softened strength gives a reasonable answer in London Clay. The reason may be inferred from Fig. 28 of the paper. The operational strength predicted by the finite element analysis is similar to the 'fully softened strength' at low normal stresses. It is lower at higher stresses, but if these slopes were re-analysed by limit equilibrium methods using a search technique then the estimated strengths would also be similar to the fully softened strength.

It is dangerous to assume that fully softened strength $\left(c^{\prime}=0\right)$ could be used successfully for other materials in other circumstances. It did not work for the Carsington failure (Skempton \& Vaughan, 1993), where it gave a safety factor for the initial collapse of $1 \cdot 2$. In this case the fully softened strength lay close to the peak strength. The operational strength is related to peak and residual strength, both of which are 'real' strengths. It must lie between them. The amount of progressive failure, quantified by the residual factor, determines where. If a limit equilibrium approach is used then it will be more consistent to adopt an average strength given by an assumed residual factor and the peak and residual strengths, together with a search technique. Results from the paper and from Carsington suggest that an average strength midway between peak and residual might be adopted as a first approach. However, this is not generally true. Analyses of dumped clay fill embankments on London clay foundations have shown that the amount of progressive failure in the foundation is much smaller than for excavated slopes in the same material.

Finite element computation becomes easier and cheaper and more widely used. The authors see no reason why it should not largely supplant limit equilibrium methods in due course. These difficulties are then overcome.

Professor Bromhead and Dr Dixon refer to the importance of the distribution of pore pressure. The authors agree with this. The magnitude and distribution of pore pressure and its development with time can be predicted as part of a finite element analysis. The value of this is apparent from the analyses 
presented in the paper. The later stages of collapse involves swelling by reduction in horizontal total stress, not by increase in pore pressure. This remains constant. Thus collapse cannot be monitored by measuring pore pressure.

The effect of the sequence of excavation is of interest. The effect of widening a motorway cutting by removing the toe of a 4:1 slope, $10 \mathrm{~m}$ high, to form a 3:1 slope overall, at different times after initial construction, has been examined. Widening greatly accelerates delayed failure and may lead to immediate failure if done 50 years or more after initial excavation. However, the amount of progressive failure as quantified by the residual factor remains about the same. As another example, cyclic seasonal stress changes within a low embankment influenced by vegetation may produce progressive failure. The analyses of dumped clay embankments referred to previously show that while there is little progressive failure during construction, it will develop in the long term as a result of nonrecoverable cyclic movement.

\section{REFERENCES}

Bromhead, E. N. (1978). Large landslides in London Clay at Herne Bay, Kent. Q. J. Engng Geol. 11, 291-304.

Bromhead, E. N. (1986). Pore water pressure manipulation in computerised slope stability analysis. Proceedings of the Midland Geotechnical Society Conference on Computer Applications in Geotechnical Engineering, pp. 175-184.

Bromhead, E. N. \& Dixon, N. (1984). Pore water pressure observations in the coastal clay cliffs at the Ise of Sheppey, England. Proc. 4th Int. Symp. Landslides, Toronto 385-390.

Bromhead, E. N., Chandler, M. P. \& Hutchinson, J. N. (1991). The recent history \& geotechnics of landslides at Gore Cliff, Isle of Wight. In Slope stability engineering - developments and applications, pp. 189-196. London: Thomas Telford.

Cooper, M. R., Bromhead, E. N., Petley, D. J. \& Grant, D. I. (1998) The Selborne cutting stability experiment. Géotechnique 48, No. 1, 83-101.

Dixon, N. \& Bromhead, E. N. (1991). The mechanics of first-time slides in the London Clay cliff at the Isle of Sheppey, England. In Slope stability engineering-developments and applications, pp. 257-262. London: Thomas Telford.

Gregory, C. H. (1844). On railway cuttings and embankments; with an account of some slips in the London Clay, on the line of the London and Croydon Railway. Minutes Proc. Inst. Civ. Engrs 3, 135-145.

Hutchinson, J. N. (1969). A reconsideration of the coastal landslides at Folkestone Warren, Kent. Géotechnique 19, 6-38.

Hutchinson, J. N., Bromhead, E. N. \& Lupini, J. F. (1980). Additional observations on the Folkestone Warren landslides. Q. J. Engng Geol. 13, $1-31$.

Hutchinson, J. N., Bromhead, E. N. \& Chandler, M. P. (1991). Investigations of the landslides at St Catherine's Point, Isle of Wight. In Slope stability engineering - developments and applications, pp. 169-179. London: Thomas Telford.

Potts, D. M., Dounias, G. T. \& Vaughan, P. R. (1990). Finite element analysis of progressive failure of Carsington embankment. Geotechnique 40, No. 1, 79-101.

Skempton, A. W. \& Vaughan, P. R. (1990). The failure of Carsington Dam. Géotechnique 43, No. 1, 151-173. 